\title{
ULTRA-SMALL CARBON SAMPLES AND THE DATING OF SEDIMENTS
}

\author{
J S VOGEL*, MADELEINE BRISKIN**, D E NELSON* \\ and \\ J R SOUTHON*
}

\begin{abstract}
Radiocarbon dates from sediment core samples are usually obtained on the whole organic carbon portion in order to use as little of the valuable sediment as possible. Such measurements may not result in an accurate chronology of the sediment because the material may include carbon from different reservoirs at the time of deposition. The development of AMS techniques for dating ultra-small $(20-500 \mu \mathrm{g})$ carbon samples permits dating various components of cored sediments. We give examples of physical and chemical fractions of sediments which illustrate the large differences in ages obtainable from materials at the same sediment depth. The dating of all or several of these fractions demands more complex interpretations than just the derivation of a sedimentation rate from whole organic carbon dates.
\end{abstract}

\section{INTRODUCTION}

We have shown that ultra-small carbon samples $(20-500 \mu \mathrm{g})$ can be ${ }^{14} \mathrm{C}$ dated, but only with decreased total measurement precision due to uncertainties in processing contamination and background (Vogel, Nelson \& Southon, 1987). However, the accuracy of the radiocarbon concentration measurement is not affected, and the date is often better associated with the event under investigation. This has been particularly beneficial in dating cored sediments where ${ }^{14} \mathrm{C}$ chronologies are usually obtained on "whole organic carbon." A precise date, using the least amount of valuable core material, is possible by measuring "whole organic carbon," but the result may be inaccurate. The dated whole carbon can often be a mixture from several reservoirs (fossil, benthic, terrestrial, etc) which have different ${ }^{14} \mathrm{C}$ ages. Further, the association of the date with the time of sedimentary deposition is not assured. We discuss here several cases in which good accuracy and association with sediment deposition were obtained by extracting and dating very specific physical or chemical carbon fractions of cored sediments.

\section{MACROFOSSIL SELECTION AND DATING}

Single-growth-year terrestrial macrofossils are physically separable carbon which are well suited to constructing accurate sediment chronologies. They have been in equilibrium with a known reservoir (the atmosphere) and generally have short transport times before deposition, depending on the watershed. Transport to the sediment was probably similar for identical macrofossils at different times. These materials also have the advantage of being immobile in the sediment, barring bioturbation, because of their size. As an example, we dated suites of chenopod seeds taken from a lacustrine sediment in western Canada (Table 1). A few

\footnotetext{
${ }^{*}$ Department of Archaeology. Simon Fraser University, Burnaby, British Columbia V5A 1S6, Canada

**Department of Geology, University of Cincinnati,Cincinnati, Ohio 45221
} 
seeds $(\approx 40 \mu \mathrm{g} / \mathrm{seed})$ from this common family were sufficient for obtaining $1 \%( \pm 80 \mathrm{yr})$ total measurement precision. Most lacustrine deposition phenomena take place on shorter time scales than $80 \mathrm{yr}$ (Håkanson \& Jansson, 1983). This precision, therefore, represented also the accuracy of the derived chronology.

TABLE 1

Examples of macrofossils used in dating sediments

\begin{tabular}{llcccc}
\hline RIDDL no. & Identification & Depth $(\mathrm{cm})$ & Size $(\mu \mathrm{g}$ carbon) & Age $(\mathrm{yr}$ BP $)$ & \pm \\
\hline Lacustrine & sediment & & & & \\
-829 & 7 Chenopod seeds & $372-382$ & 250 & 1060 & 75 \\
-830 & 8 Chenopod seeds & $915-920$ & 410 & 3600 & 75 \\
Boreal climate indicators & & & & \\
-815 & 2 Betula papyrifera seeds & 825 & 52 & 10,430 & 380 \\
-817 & 1 Picea needle & 855 & 78 & 10,230 & 220 \\
-819 & 5 Betula papyrifera seeds & 875 & 48 & 10,470 & 440 \\
-816 & Unid. woody fragment & 825 & 230 & & 100 \\
-818 & Unid. woody fragment & 855 & 120 & 3860 & 120 \\
-819 & Unid. woody fragment & 875 & 160 & 3490 & 100 \\
Charred barley grain & & & & \\
-888 & Barley seed & & 720 & 5220 & 100 \\
-889 & Barley seed acid wash & & 1000 & 5360 & 130 \\
-890 & Barley seed base wash & & 1200 & 5150 & 130 \\
Fungus & & & & & \\
-867 & Fungus cluster & & 215 & 20,600 & 1100 \\
-868 & Fungus cluster base wash & & 320 & 17,270 & 460 \\
\hline
\end{tabular}

The identification of the macrofossils is helpful in establishing that materials are associated with the phenomena under study. Unidentified samples cannot be so judged for their contextual relevance. For example, a study of climatic fluctuations resulted in data in Table 1 . The ages of unidentifiable woody materials disagreed with those for smaller, identified macrofossils which were found at the same levels. The macrofossils were direct indicators of the Boreal environment under investigation (Peteet $\mathrm{et} \mathrm{al}$, ms) whereas the woody materials were only thought to be associated with them. Mixing both materials from each level would have provided better measurement precision by increasing the sample size. Clearly, the results from such mixed samples would have been inaccurate with no association to the subject being studied. We now know that the woody fragments were introduced during coring. This was an extreme example of misplaced association threatening the accuracy of a chronology.

A more common problem is the contamination of macrofossils by chemically mobile contaminants. By comparing the ages of organic materials removed during acid and alkali washes with the age of the prepared sample, the level of contaminants remaining in the treated portion can be 
estimated (Batten et al, 1986). Table 1 gives an example of a portion of a charred barley grain associated with an unlikely stratum in a sediment. The ages of the acid and base washes and the residue were within $1 \sigma$ of each other, indicating that we accurately measured the age of the seed. Another example was a small fungus cluster found in clay sediments from the northern Queen Charlotte Islands of Canada (Table 1). The fungus was not as impermeable to contaminants as were seeds or cellulose. More than half the sample was soluble in base $(0.25 \mathrm{~N} \mathrm{NaOH})$ and this portion was $3 \mathrm{ka}$ younger than the insoluble part. However, the accurate age of the fungus would lie within the stated precision, even if up to $20 \%$ of the treated fungus were still composed of humic contaminants. Since the final base wash was not discolored, this was unlikely.

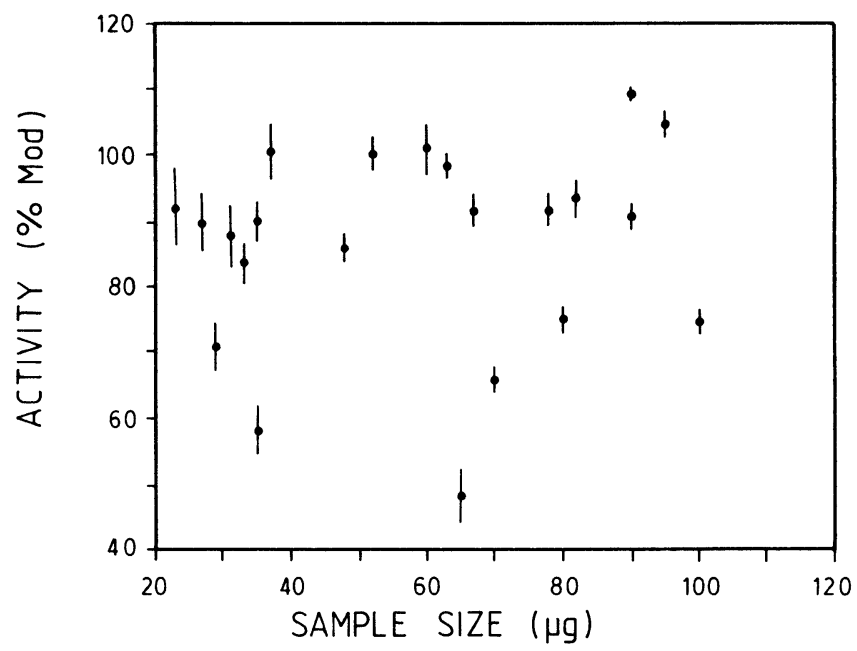

Fig 1. Final ${ }^{14} \mathrm{C}$ concentrations as a function of carbon sample size for 22 samples $<100 \mu \mathrm{g}$ from a study of the ecosystem around a marine oil seep. ${ }^{14} \mathrm{C}$ concentrations were measured to a precision of $1-2 \%$. Final precisions were $3-8 \%$ after size-dependent background subtraction.

We recently studied living meio- and macrofauna from cored sediments in order to follow fossil carbon through the ecosystem around an oil seep (Bauer, Spies \& Vogel, ms). Dissolved inorganic carbon in $1-5 \mathrm{cc}$ of porewaters from these sediments were also analyzed, as were lipids and total organic carbon. Figure 1 shows the activity and final precision for the 22 samples containing $20-100 \mu \mathrm{g}$ of carbon in this study. Precisions of 1 to $2 \%$ were obtained in the ${ }^{14} \mathrm{C}$ concentration measurements, with total measurement precision of $3-8 \%$ arising from the uncertainty in the background subtraction. These precisions were entirely adequate to distinquish the path of fossil carbon through the local ecosystem. The use of ultra-small samples provided details which would have been masked by larger, less specific samples. 


\section{CHEMICAL FRACTIONS IN MARINE SEDIMENTS}

Two cores, one from the Black Sea and one from the Gulf of California, were used to study chemical fractions in marine sediments.

\section{Black Sea Core}

The Black Sea core (Atlantis II, \#1443, Ross \& Degens, 1974) was previously used in a study of sapropel formation and only a few hundred milligrams of sediment from each level were available for analysis. We studied a base soluble fraction $(0.25 \mathrm{~N} \mathrm{NaOH}$ with sonication $)$ and the residual sediment along with the original whole organic carbon dates (Table 1 and Fig 2). The depth of the carbon-rich sapropel is obvious from the carbon con-

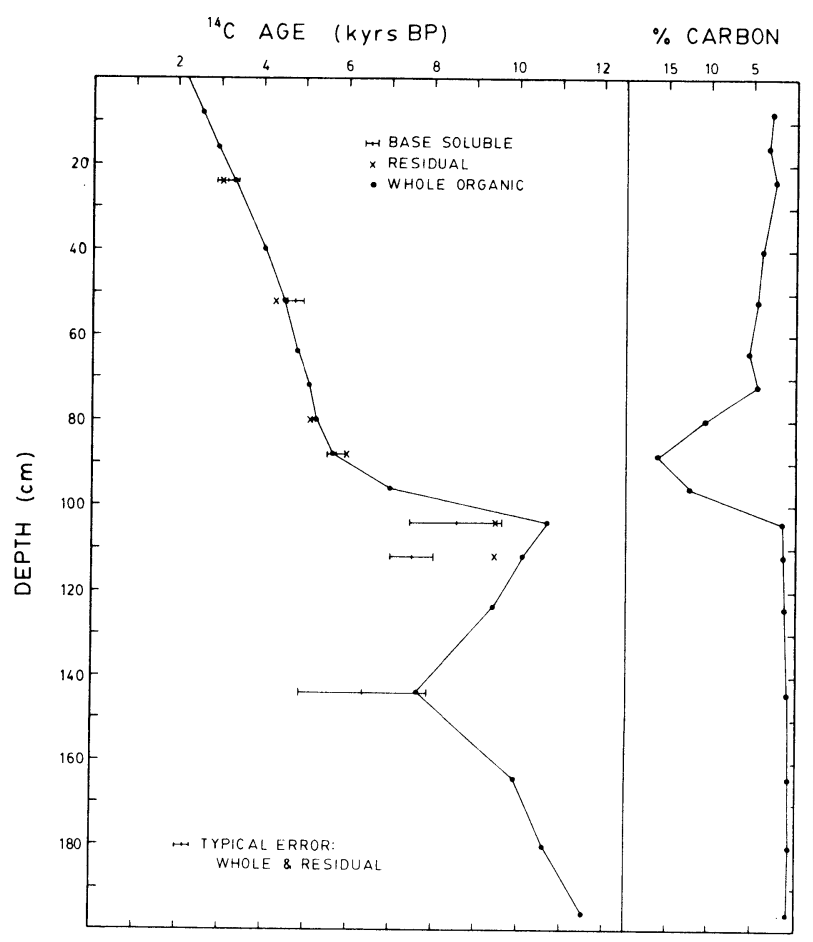

Fig. 2. The ${ }^{14} \mathrm{C}$ age $v s$ depth for whole organic carbon, base-soluble fraction, and residual sediment from core 1443 from the Black Sea. The organic carbon content of the core is also shown, indicating the carbonrich, sapropelic layer. Humic material from the sapropel diffused into the older carbon sediment below 100 $\mathrm{cm}$.

centration. We have seen older carbon in the sediment below a sapropel in another Black Sea core (Calvert, Vogel \& Southon, 1987) but not as distinctly as in this example. The transition from the older layer to the sapropel provided a step function around which carbon mobility could be studied, since the anoxic conditions of the Black Sea prevent benthic mixing. Humic material was separated from the whole sediment for 7 of the 17 available 
strata. Sample sizes for these humic samples ranged from $260 \mu \mathrm{g}$ down to $18 \mu \mathrm{g}$, and the final measurement precisions reflected these sizes. The humic fractions in and above the sapropel were equal in age to the whole organic carbon, indicating an autochthonous source. The humics extracted from the older carbon-poor layer below the sapropel were significantly younger than the whole organics. This suggested that the base soluble carbon from the overlying sapropel was mobile and diffusing into the older sediment, as

TABLE 2

Black Sea Core 1443 organic carbon ages

\begin{tabular}{|c|c|c|c|c|c|}
\hline RIDDL no. & Identification & Depth $(\mathrm{cm})$ & $\operatorname{Size}^{*}$ ( $\mu \mathrm{g}$ carbon $)$ & Age (yr BP) & \pm \\
\hline-285 & Whole organic & 24 & & 3310 & 200 \\
\hline-1043 & Base soluble fraction & & 65 & 3140 & 240 \\
\hline-1044 & Residual sediment & & & 3060 & 90 \\
\hline-287 & Whole organic & 52 & & 4490 & 170 \\
\hline-375 & Base soluble fraction & & 260 & 4720 & 200 \\
\hline-1045 & Residual sediment & & & 4290 & 140 \\
\hline-290 & Whole organic & 80 & & 5240 & 90 \\
\hline-1046 & Base soluble fraction & & & 5210 & 80 \\
\hline-1047 & Residual sediment & & & 5140 & 100 \\
\hline-291 & Whole organic & 88 & & 5660 & 170 \\
\hline-377 & Base soluble fraction & & 670 & 5680 & 170 \\
\hline 293 & Whole organic & 104 & & 11,130 & 100 \\
\hline-1048 & Base soluble fraction & & 22 & 8530 & 1080 \\
\hline-1049 & Residual sediment & & & 9460 & 120 \\
\hline-294 & Whole organic & 112 & & 10,080 & 210 \\
\hline-379 & Base soluble fraction & & 50 & 7490 & 500 \\
\hline-1050 & Residual sediment & & & 9000 & 120 \\
\hline-296 & Whole organic & 144 & & 7620 & 170 \\
\hline-1051 & Base soluble fraction & & 18 & 6340 & 1500 \\
\hline-1052 & Residual sediment & & & 7670 & 120 \\
\hline
\end{tabular}

${ }^{*}$ Size is given only for samples $<1000 \mu \mathrm{g}$.

could be expected in the basic $(\mathrm{pH} \approx 8.1)$ marine environment. The data were compatible with a diffusion length of $\approx 10 \mathrm{~cm}$, assuming the humic content of the sediments to be $10 \%$.

The "residue" sediment after humic extraction was generally younger than the whole organic carbon date, but significantly so only for the two strata below the sapropel. This may have been a contamination artifact of the base wash. The extraction was not done in an inert atmosphere, although all portions were well acidified prior to combustion. Atmospheric exchange with organic carboxylic acids during the base extraction was tested 
on a 130ka sediment from the Panama basin. The non-humic residue was $4.5 \%$ more modern than the inorganic fraction, more than enough to explain the smaller differences in the Black Sea core.

\section{Gulf of California Core}

The core from the Gulf of California (DSDP or ODP ${ }^{* 480)}$ was supplied in 3cc portions. The samples were thin sections taken across the core at well-defined varves, as indicated by nuclear magnetic resonance imaging (Briskin et al, 1986). An aliquot of $1-1.5 \mathrm{~g}$ from each depth was used to obtain various organic fractions. The lipids were removed by dissolution in chloroform during 320 -min rinses with sonication. The chloroform was slowly evaporated from both the extracted lipids and the residual sediment in air and further evaporated under vacuum at $80^{\circ} \mathrm{C}$ overnight. The sediment was then hydrolyzed for $1 \mathrm{hr}$ with sonication in $6 \mathrm{~N} \mathrm{HCl}$. The hyd-

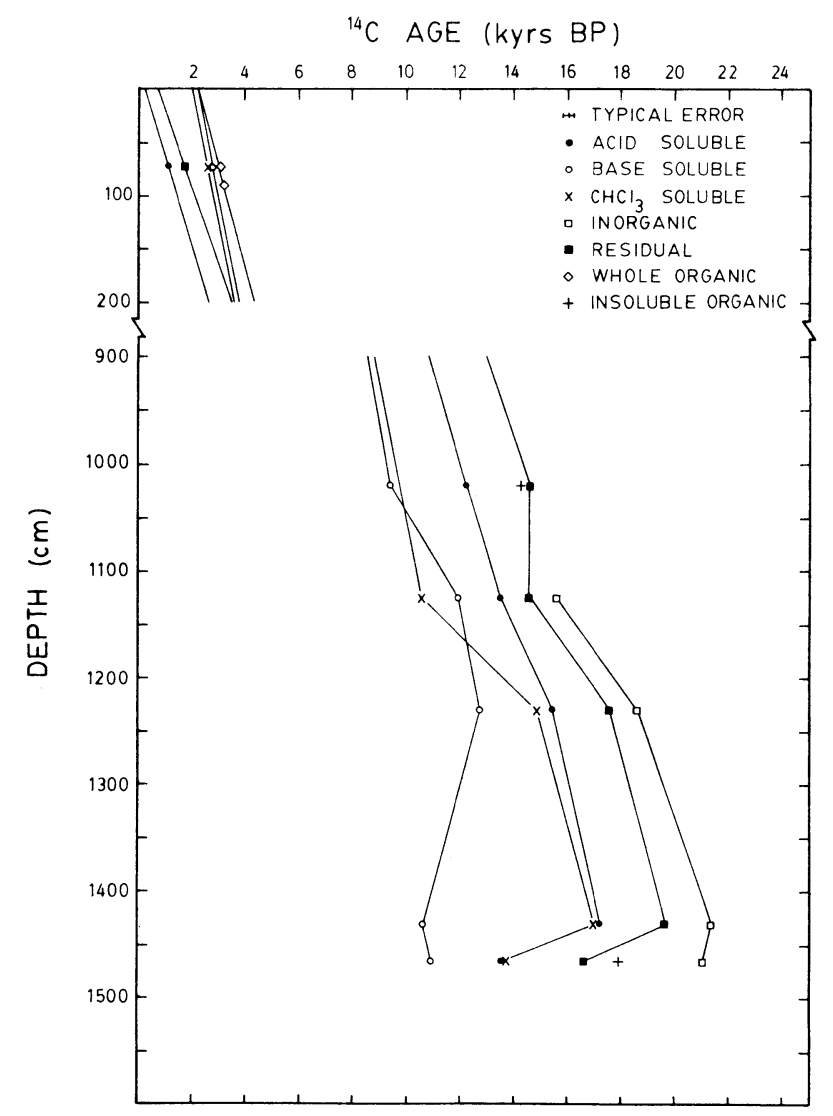

Fig. 3. The ${ }^{14} \mathrm{C}$ age $v s$ depth for chemical fractions of the carbon in ODP core 480 from the Gulf of California. The wide disparity in ${ }^{14} \mathrm{C}$ ages at each depth demonstrated the chronologic inaccuracy introduced by dating the whole organic carbon from such a core. 
rolysate was brought to $\mathrm{pH} \approx 5$ using $\mathrm{NaOH}$, centrifuged, decanted slightly and evaporated to dryness. The rinsed sediment was then sonicated in $0.1 \mathrm{~N}$ $\mathrm{NaOH}$ plus $0.1 \mathrm{M} \mathrm{Na} \mathrm{P}_{4} \mathrm{P}_{2} \mathrm{O}_{7}$ for $1 \mathrm{hr}$ to extract humic materials. Ramunni and Palmieri (1985) showed that such treatment is equivalent to a 24-hr soak. The solute was acidified and the precipitate was separated and dried. The final sediment residue was also acidified and dried. All materials were combusted in sealed tubes with $\mathrm{CuO}$ at $900^{\circ} \mathrm{C}$. The bulk inorganic carbonate was dated by hydrolyzing a portion with $85 \% \mathrm{H}_{3} \mathrm{PO}_{4}$.

In contrast to the Black Sea sediments, components of the Gulf of California core possessed an extremely wide range of ages at each depth, as shown in Figure 3. No unique age could be assigned to the strata, but ${ }^{14} \mathrm{C}$ could be used as a geochemical tracer to understand the processes at work in the Gulf. The studied interval was chosen to include the Pleistocene/ Holocene boundary as indicated by preliminary dating (Shackleton Hall, 1982; Spiker \& Simoneit, 1982). The influx of older material at ca $1450 \mathrm{~cm}$ was probably due to increased erosional activity at that time. The similar trends in the ages of the individual chemical fractions indicated a relatively stable but allochthonous source of carbon in this sediment through the early Holocene.

Whole organics were dated for two shallow strata and were older than the extracts. At the shallowest stratum, the residual was younger than the whole organic carbon and two of the extracted components, although no balancing old component was found. Exact sonochemical effects on sediment extractions have not been well researched and may be responsible. The largest fraction of carbon was the acid/base/solvent insoluble residue. This residue was the oldest organic component at early Holocene depths and was separable gravimetrically into components attached and unattached to clay particles. Even these two fractions had detectably different ages ("Residual" and "Insoluble Organic" in Fig 3). Carbon compounds which were that immune to separation from clay particles could have been on these particles long before deposition. If such compounds are dominant in a "whole organic carbon" date, they provide only an upper limit to the time of deposition.

Except near the top of the core, humic materials were younger than other fractions which are their presumed chemical precursors (Ishiwatari, 1985; Vandenbroucke, Pelet \& Debyser, 1985). These data and the high ${ }^{14} \mathrm{C}$ activity of that fraction at $1430 \mathrm{~cm}$ could be explained by the mixing of materials of different ages. Exchange with atmospheric $\mathrm{CO}_{2}$ during base extraction was insufficient to explain the extreme youth of this material. As with the Black Sea sediment, the humic portion appeared to be mobile. Our data did not cover sufficient distances to determine a diffusion length, which must be large, judging by the youth of the base soluble fraction and the high sedimentation rate $(\approx 100 \mathrm{~cm} / \mathrm{kyr})$. The mobility of this fraction indicated that humic acids must either be dated separately or removed before dating a marine sediment core.

The components (amino acids, carbohydrates, etc) released by acid hydrolysis (Degens, Reuter \& Shaw, 1964) were younger than the clayattached carbon but older than the base or solvent soluble fractions. This fraction is chemically imprecise and dependent on the hydrolysis procedure (Vandenbroucke, Pelet \& Debyser, 1985). The hydrolysates were the 
smallest fractions extracted, 120 to $220 \mu \mathrm{g}$ of carbon, but this fraction had the most stable age/depth trend and the lowest extrapolated age at the sediment surface. More research is needed to determine if this fraction could yield accurate chronologies.

Fowler, Gillespie and Hedges (1986) suggest that lipids are the best material for dating sediments. Lipids are primary compounds produced by plants and animals, and are in near equilibrium with atmospheric or marine $\mathrm{CO}_{2}$ at the time of production. They are less mobile than inorganically soluble molecules. Ishiwatari (1985) shows that lipids are a precursor to humic and humin substances. Except for reservoir effects, they should be the youngest immobile fraction in a sediment, as they were here. They should provide the most accurate measure of the time of deposition. Since $50-100 \mu \mathrm{g}$ of carbon extracted as lipids from a single core can be accurately dated, "bulking samples from several cores" (Fowler, Gillespie \& Hedges, 1986, p 449) to obtain large amounts of lipids is not necessary. The larger sample may give better measurement precision, but the bulking process might mix lipids of different ages, destroying the accuracy of the result.

The ODP 480 core showed that several carbon fractions with disparate ${ }^{14} \mathrm{C}$ concentrations can be separated from some sediments. Only one, or perhaps none, of these fractions may provide an accurate chronology of deposition, while the others provide evidence of their source or transport. In any event, $\mathrm{a}^{14} \mathrm{C}$ age taken on whole organic carbon from such a sediment will be inaccurate, no matter how precise the ${ }^{14} \mathrm{C}$ measurement.

\section{CONCLUSION}

Core chemistries and macrofossils must be studied carefully so that a carbon fraction derived from a known reservoir may be selected for dating purposes. The more identified a fraction is, the smaller it will be. Ultrasmall sample techniques are now making this selectivity possible, resulting in significant improvements in the accuracy and the association of ${ }^{14} \mathrm{C}$ measurements on sediment cores.

\section{ACKNOWLEDGMENTS}

We would like to thank the staff and our colleagues at the McMaster University Tandem Lab for their continued help with our AMS program; Dorothy Peteet, Columbia University, for the use of her sample data; Tom Pedersen, University of British Columbia, for a section of his Panama Basin sediment and for his numerous $\delta^{13} \mathrm{C}$ measurements using his new Micromass spectrometer; Steve Calvert, University of British Columbia, for the remains of his Black Sea core; and the Ocean Drilling Program for the samples from core 480 . Herminia Roman helped with sample preparation and measurement. This research was supported by NSERC of Canada, RIDDL, Simon Fraser and McMaster Universities. 


\section{REFERENCES}

Batten, R J, Gillespie, R, Gowlett, J A J and Hedges, R E M, 1986, The AMS dating of separate fractions in archaeology, in Stuiver, $\mathrm{M}$ and Kra, RS, eds, Internatl ${ }^{14} \mathrm{C}$ conf, 12 th, Proc: Radiocarbon, v 28, no. 2A, p 698-701.

Bauer, J E, Spies, R B and Vogel, J S, ms, Natural ${ }^{14} \mathrm{C}$ abundances in microgram samples of organic, dissolved inorganic and faunal carbon in sediments associated with marine petroleum seepage: $\mathrm{ms}$ subm to Science.

Briskin, M, Robins, J, Reidel, W R and Booker, R, 1986, Magnetic resonance imaging analyses of varved marine sedimentary records of the Gulf of California: Geophys Research Letters, v 13, p 753-756.

Calvert, S E, Vogel, J S and Southon, J R, 1987, Carbon accumulation rates and the origin of the Holocene sapropel in the Black Sea: Geology, v 15, p 918-921.

Degens, E T, Reuter, J H and Shaw, K N F, 1964, Biochemical compounds in offshore California sediments and sea water: Geochim et Cosmichim Acta, v 28, p 45-66.

Fowler, A J, Gillespie, R, and Hedges, R E M, 1986, Radiocarbon dating of sediments, in Stuiver, $\mathrm{M}$ and Kra, R S, eds, Internatl ${ }^{14} \mathrm{C}$ conf, 12th, Proc: Radiocarbon, v 28, no, 2A, p $441-450$.

Hakanson, L and Jansson, M, 1983, Principles of lake sedimentology: Berlin, Springer-Verlag, p 237.

Ishiwatari, R, 1985, Geochemistry of humic substances in lake sediments, in Aiken, G R, McKnight, D M, Wershaw, R L and MacCarthy, eds, Humic substances in soil, sediment, and water-geochemistry, isolation and characterization: New York, John Wiley \& Sons, Inc, p 147-180.

Peteet, D M, Vogel, J S, Nelson, D E, Southon, J R, Nickman, R J and Heusser, L E, ms, AMS ${ }^{14} \mathrm{C}$ dating of macrofossils indicates presence of Younger-Dryas climatic reversal in northeastern USA: ms subm to Quaternary Research.

Ramunni, A U and Palmieri, F, 1985, Use of ultrasonic treatment for extraction of humic acid with inorganic reagents from soil: Organic Geochem, v 8, p 241-246.

Ross, D A and Degens, E T, 1974, Recent sediments of Black Sea, in The Black Sea-geology, chemistry and biology: Am Assoc Petroleum Geologists, mem 20, p 183-199.

Shackleton, $\mathrm{N} J$ and Hall, M A, 1982, Oxygen isotope study of continuous scrape samples from site 480: Initial repts deep sea drilling proj, v 64, pt 2, p 1251-1254.

Spiker, E C and Simoneit, B R T, 1982, Radiocarbon dating of recent sediments from leg 64, Gulf of California: Initial repts deep sea drilling proj, v 64, pt 2, p 757-758.

Vandenbroucke, M, Pelet, R and Debyser, Y, 1985, Geochemistry of humic substances in marine sediments, in Aiken, G R, McKnight, D M, Wershaw, R L and MacCarthy, eds, Humic substances in soil, sediment, and water - geochemistry, isolation and characterisation: New York, John Wiley \& Sons, Inc, p 249-273.

Vogel, J S, Nelson, D E and Southon, J R, 1987, ${ }^{14} \mathrm{C}$ background levels in an accelerator mass snectrometry system: Radiocarbon, v 29 , no. 3, p 323-333. 